\title{
ALGUNS SUPORTS PER A LA RECERCA
}

\author{
Teresa Torns i Tina Brullet
}

En els darrers temps la inevitabilitat d'acceptar que les innovacions: tecnològiques envaeixin qualsevol àmbit de la nostra vida sembla fora de discussió. I si concretem aquesta inevitabilitat en els avantatges que aquestes innovacions ofereixen en el camp de la informació i de la documentació com a eines de suport a la recerca, resulta immediat parlar de bases de dades documentals $\mathrm{i} / \mathrm{o}$ de centres de documentació especialitzats en el tema de la dona.

Qualsevol investigadora o investigador coneix la importància de tenir un bon suport documental entorn la informació que precisa per a la seva recerca. Especialment quan la recerca es desenvolupa en un àmbit específic, però alhora necessitat d'una visió fortament multidisciplinaritzada, com és el tema de la dona. És per això que, conscients d'aquesta necessitat, la majoria dels grups d'estudis sobre la dona que han anat sorgint al país, en aquests darrers deu anys, han dedicat bona part dels seus esforços a la recopilació d'informació i documentació pròpia de la seva especialitat.

De tal manera que avui en dia podem comptar amb un bon nombre de centres de documentació de continguts i funcionament força diversos. A tall d'exemple citarem, en primer lloc, el que funciona donant suport al Seminario de Estudios de la Mujer de la Universidad del País Vasco, amb seu a Donosti. Aquest centre, que començà les seves activitats l'any 1986, és, malgrat la seva recent creació, un dels més actius. Té a l'actualitat un fons documental de 1.193 publicacions, 445 documents diversos, 14 subscripcions a revistes espanyoles i estrangeres, a més de 13 vídeos i més 
de 500 fotografies. Manté contactes amb altres entitats similars i els seus projectes palesen les possibilitats d'una política infrastructural ben dotada.

En segon lloc cal citar el suport documental que forma part del Centre d'Història de la Dona, dirigit per Mary Nash, de la Universitat de Barcelona. Es tracta d'un centre ben dotat de recursos humans i materials que ha recopilat un dels fons de documents escrits i gràfics entorn la història de la dona més importants de l'Estat espanyol. El centre gaudeix, a més, de la tasca de recerca portada a terme per investigadores que treballen conjuntament amb la directora. L'entitat manté, a més, contactes periòdics amb investigadores d'altres indrets que habitualment collaboren amb les activitats externes del centre.

En l'àmbit universitari cal citar també el que està ubicat a la Universitat Autònoma de Barcelona dins del Seminari d'Estudis de la Dona. Aquest centre no té fons documental propi, però compta com a eina més important amb la base de dades DONUA, i té com a objectiu prioritari oferir informació documental per a la recerca. A nivell institucional, hem d'esmentar obligadament el que des de la seva fundació va impulsar l'Instituto de la Mujer a Madrid. A l'actualitat aquest és un dels centres més ben dotats pel que $\mathrm{fa}$ al seu fons ( 9.200 volums) i al nombre i qualitat de les seves subscripcions a revistes espanyoles $\mathrm{i}$ internacionals (185 subscripcions de revistes i prop de 70 subscripcions de revistes de sumaris). Publica mensualment un butlletí de sumaris, un butlletí de documentació i breus ressenyes de les novetats bibliogràfiques. Compta, a més, amb una base de dades documental -BIMU - que és accessible on-line des de qualsevol PIC del Ministerio de Cultura.

També cal fer esment del Centre de Documentació de la Dona que l'Ajuntament de Barcelona fa funcionar al centre cívic de La Sedeta d'aquesta ciutat, que funciona donant suport informatiu $i$ documental a investigadores $i$ estudiosos en general. De característiques similars al centre de documentació de Donosti per la qualitat de la tasca desenvolupada, però no tan directament lligat al món universitari, és el Centre de Documentació, Recerca i Iniciativa de la Dona que funciona a la ciutat de València des de l'any 1983. I per acabar cal que recordem altres centres lligats a iniciatives portades a terme per grups de dones sense suports institucionals. En són una mostra el Centro de Investigación y Formación Feminista de Madrid i el Centro Feminista de Estudios y Documentación també de Madrid. 


\section{L'EXPERIĖNCIA DEL SEMINARI D'ESTUDIS DE LA DONA (SED) DE LA UAB}

Les components del Seminari d'Estudis de la Dona de la Universitat Autònoma de Barcelona impulsaren la creació d'un centre de documentació l'estiu del 1982, mogudes per la ja esmentada necessitat d'iniciar els estudis sobre la dona des d'una òptica multidisciplinar. En uns primers moments, el projecte d'aquest centre va estar dedicat prioritàriament a la confecció d'un llistat de lilibres capaç de recuperar la informació documental bàsica existent a Espanya fins al moment. Els criteris que van orientar aquella primera recerca foren que la informació estigués centrada en el tema de la dona i orientada des del marc general de les ciències socials. D'aquesta manera es volia aconseguir un fons d'informació documental que, prenent com a base la llista obtinguda, estigués disponible per a les futures recerques de les components del Seminari $i$ altres investigadors/es tant de dins com de fora de la Univesitat.

El projecte comptava amb una subvenció que la Generalitat de Catalunya havia concedit aquell any al SED. Cal fer a més esment que des de l'inici es va poder comptar amb el suport tècnic del Consorci d'Informació i Documentació de Catalunya. Els resultats d'aquesta primera fase de treball, gràcies precisament a la qualitat del suport de la gent del CIDC, en especial d'Isidre Canals, van concretar-se en la publicació d'un repertori bibliogràfic informatitzat. ${ }^{1}$ Aquest repertori recollia la documentació en castellà, català, gallec i basc editada a Espanya des de 1970 fins a 1982 . Una sèrie d'indexs classificats segons autors, títols, temes, tipus de document, biblioteca $i$ unes fitxes bibliogràfiques completes ordenades per any d'edició, proporcionaven una gran riquesa a l'hora de cercar la informació.

Però aquest primer pas no va ser el definitiu, perquè l'intent de confegir una primera bibliografia bàsica va convertir-se en un projecte molt més ambiciós: la creació d'una base de dades documental que aprofités el material recopilat a l'esmentat repertori. El suport econòmic aquesta vegada va arribar des de l'Instituto de la Mujer de Madrid i el CIDC va posar al nostre abast el potencial del software BASIS. Els treballs de conversió i redefinició d'aquells primers llistats d'ordinador van donar com a resultat la base de dades DONUA.

1. C. Brullet - T. Torns, La dona: Repertori bibliográfic (1970-1982), Barcelona, SED-UAB, 1983, 418 pp. 


\section{LA BASE DE DADES DONUA}

La base de dades DONUA té a l'actualitat, aproximadament, unes mil cent referències bibliogràfiques sobre documents publicats a Espanya en castellà, català, basc i gallec des de l'any 1970 fins al 1986. Els criteris cronològics, temàtics $i$ de tipus documental utilitzats per configurar la informació foren els mateixos que varen definir l'elaboració del repertori abans comentat. Per tant, això vol dir que DONUA té informació bibliogràfica sobre llibres, revistes feministes, jornades i congressos, i monogràfics o dossiers que s'hagin editat entre les dues dates esmentades. Cal precisar només que la primera d'elles - 1970 - només ha estat ultrapassada per aquells documents, generalment llibres, que, tot $i$ haver estat publicats abans d'aquest any, la seva importància els ha convertit en clàssics. I que el retard en la incorporació del material aparegut des del 1987 fins ara té a veure amb les dificultats de tipus econòmic que el funcionament d'un centre d'aquestes característiques presenta.

La base de dades DONUA està en aquests moments en procés d'ampliació mercès als resultats de recerca documental que el SED ha portat a terme els anys 1985 i 1986. Aquesta recerca, que també va comptar amb la subvenció de l'Instituto de la Mujer, va possibilitar, en una primera fase, el buidatge de tots els llibres existents a les biblioteques de la UAB relacionats amb el tema de la dona o d'interès per aquest tema. Aquest buidatge va suposar revisar més de 200.000 fitxes i obtenir com a resultat 925 títols que a l'actualitat estan informatitzats però no incorporats definitivament a la base. La seva incorporació suposarà la creació d'un subapartat a DONUA que, sota el nom de MULIER, podrà tenir entitat pròpia i que, amb criteris iguals per a la selecció i l'organització de la informació, presenta únicament diferències pel que fa a la cronologia (no hi ha data límit) i a les llengües (pel fet de tractar-se dels fons de la $U A B$, lògicament, encara que escassos, hi ha llibres en les principals llengües estrangeres). En una segona fase aquest buidatge va afrontar la recerca d'articles de les revistes de ciències socials presents a les hemeroteques de la UAB. Es van buidar 105 revistes i fins a l'any 1986 s'han comptabilitzat uns 2.400 articles que a l'actualitat estan pendents de gravació $\mathrm{i}$ incorporació a DONUA dins del subapartat MULIER.

En un futur immediat el centre de documentació del SED té entre els seus projectes l'elaboració de perfils bibliogràfics especialitzats per temes. En aquesta línia, existeix ja un primer perfil que recull la informació dels documents més important existents a Espanya i a l'estranger entorn del tema de la dona i l'educació. La necessitat que en aquest cas concret va fer aparèixer la demanda va ser una sèrie de recerques que sobre el tema de 
la dona i l'educació havien estat realitzant algunes membres del SED. Aquest material en aquests moments està informatitzat $i$ pendent de ser incorporat a DONUA, mantenint també entitat pròpia sota el nom d'EDUCA.

$\mathrm{La}$ interrogació de la base pot realitzar-se a l'actualitat al Consorci d'Informació i Documentació de Catalunya, perquè està físicament implementada en l'ordinador d'aquesta entitat. També pot interrogar-se des dels terminals de la $\mathrm{UAB}$ tot $\mathrm{i}$ que aquesta tasca es troba, encara, malauradament, en període experimental. Les dificultats de la connexió estan motivades per la implantació de les noves xarxes de comunicació en aquesta universitat $\mathrm{i}$ per les tasques d'adaptació del contingut de la pròpia base a les normes del CCF. Les possibilitats de recuperar la informació són, però, molt efectives $i$ en els projectes de futur està previst que la consulta de la base pugui fer-se des de qualsevol terminal d'ordinador convenientment connectat. Els problemes que s'han de vèncer, tot i ser importants, no superen, pensem, els que hem hagut d'afrontar des del començament.

Aquesta reflexió, que pot semblar poc matisada per qui desconegui la grisor $i$ les dificultats del treball documental, d'alguna manera reflecteix tot el procés sofert per les tasques que el SED ha dut a terme, en aquest sentit. Les persones que hem collaborat en aquesta tasca des del seu començament som conscients que la majoria de problemes d'ordre tècnic que hem hagut de solucionar han estat derivats de la nostra inexperiència documental $i$ informàtica. Arribar a comprendre que per donar un bon suport a la recerca en el tema de la dona calia assolir els criteris que feien que una pila de dades (en aquest cas concret una llista de llibres) es convertís en una base de dades consultable on-line no ha estat ni senzill ni immediat. El suport del CIDC ha estat decisiu i ha ajudat perquè algunes membres del SED passessin del desconeixement relatiu en temes d'informàtica documental a una certa fascinació. Una fascinació que, cal dir-ho, hem anat comprovant que també compartíem amb bona part de les dones que hem anat coneixent en els contactes establerts amb els centres de documentació citats a l'inici d'aquest escrit. Però també cal dir que de l'ambició sorgida perquè aquell primer llistat de llibres fos alguna cosa més, informàticament parlant, han sorgit també molts inconvenients, i no tots precisament d'ordre tecnològic. Perquè, contràriament al que hom pensa, aquests problemes quan es presenten acostumen a tenir solucions relativament assequibles.

Ens volem referir, com no, als problemes de tipus teòric $\mathrm{i}$ ideològic que ens han sorgit fonamentalment a l'hora d'afrontar la classificació temàtica dels documents. En un primer cop d'ull, la feblesa dels descriptors que hem emprat pot atribuir-se a la inexperiència de les persones que vàrem iniciar la recerca documental. Però és més cert que aquesta inexpe- 
riència aviat va tenir un sostre produït per la inexistència d'eines prou apropiades. En concret, volem referir-nos a la CDU, classificació decimal universal, que hom pot trobar a qualsevol biblioteca especialitzada i que pel que fa al tema de la dona mostra la seva total ineficàcia, donat el sexisme i l'androcentrisme que l'emparen. En aquests moments no hi ha a nivell de l'Estat cap thesaure que funcioni a plena satisfacció de les investigadores i documentalistes. Sabem de l'existència d'un thesaure que Montserrat Sebastià, collaboradora del centre dirigit per Mary Nash, va elaborar pel que fa al tema de la dona $\mathrm{i}$ la Historia $\mathrm{i}$ dels intents que a l'Instituto de la Mujer s'han anat produint per solventar la qüestió. Però la realitat actual, pel que fa a l'Estat espanyol, mostra la necessitat de crear un thesaure general no sexista que permeti sistematitzar una informació documental específica de manera no discriminatòria.

Sabem que aquesta és una necessitat compartida per totes les dones que han tractat la qüestió. El SED, en el seu dia, va impulsar un grup de treball que no va arribar a bon port. Aquest grup pretenia debatre les qüestions teòriques $\mathrm{i}$ ideològiques d'un objecte d'estudi que no tothom reconeix $\mathrm{i}$ que enfonsen les seves arrels en el sexisme i l'androcentrisme que presenta tot el coneixement en general. Mentrestant, tot i la precarietat present en aquest terreny, la classificació temàtica emprada a la base de dades DONUA ha sorgit de la traducció i l'adaptació d'alguns encapçalaments del thesaure que Joan K. Marshall publicà el 1977 sota el títol On Equal Terms: Thesaurus for Nonsexist Indexing and Cataloging. ${ }^{2}$ No és la solució ideal, però és un possible camí que estem convençudes que cal compartir amb d'altres especialistes. Algunes fins i tot esperem poder fer-lo en comú sota l'impuls d'alguna entitat que tingui la voluntat i els mitjans per impulsar un projecte d'aquesta volada. Però aquestes i d'altres qüestions que afecten els futurs projectes de recerca documental del SED remeten en general a les queixes que totes les investigadores i investigadors d'aquest país, dedicats en especial al tema de la dona i en general a l'àmbit de les ciències socials, podríem subscriure.

Entre aquestes queixes hi ha, com és fàcil preveure, les relatives al finançament del projecte. Unes queixes que no pel fet de ser citades en darrer terme han de ser interpretades com les menys importants. Cal precisar que totes les activitats dutes a terme pel SED no han tingut altres recursos econòmics que les ajudes $\mathrm{i}$ subvencions que hem anant obtenint d'alguns organismes oficials i que, per tant, la precarietat i la discontinuitat han estat en consequiència les característiques més significatives de la globalitat del projecte. Sabem que aquest és un greuge compartit per la

2. New York, Shuman Publishers Inc., 1977. 
majoria de companys i companyes que es dediquen a la investigació d'objectes d'estudi considerats com a poc rellevants. Només voldríem afegir com a anècdota el fet que en aquest cas, tot $i$ estar apuntades al carro de les noves tecnologies, que segons el discurs dominant és molt bon vehicle, no fa més que evidenciar una vegada més que el rei va nu.

\section{PROJECTES DE FUTUR}

De tota manera, els projectes per tirar endavant la infrastructura documental SED continuen existint perquè creiem en la necessitat de dur a terme aquest tipus de tasca. A més dels ja esmentats, estem tractant de potenciar un nou projecte de suport a la recerca que ens permeti establir les connexions amb altres bases de dades existents arreu de l'Estat i a l'estranger. En aquest sentit, vàrem establir des del començament contactes amb el centre de Viena de la UNESCO, i una membre del SED va ser convidada a assistir al «VI Training Seminar» del centre que va tenir lloc l'abril de 1987 a Moscou. En aquest seminari es tractaren qüestions relatives a les necessitats d'informació, problemes i possibilitats en la recerca comparada al camp de les ciències socials. La trobada va suposar l'establiment de contactes amb investigadores $\mathrm{i}$ investigadors interessats especialment en l'àmbit de la dona i de la documentació i la constatació de l'interès creixent pel tema. El centre de Viena va insinuar la possibilitat de configurar un àmbit específic sobre la matèria, i les expectatives són nombroses.

A nivell més proper, $\mathrm{i}$ reprenent el discurs sobre les dificultats de refer les eines bàsiques (thesaure) i d'unificar criteris i esforços, s'està pendent d'un projecte que permeti realitzar una segona trobada sobre dona i documentació a nivell de tot l'Estat. Aquesta trobada suposaria reprendre un contacte amb totes les persones interessades, que fins ara només ha. pogut continuar-se amb caràcter esporàdic amb alguns dels centres, i la possibilitat d'intercanviar opinions i experiències. No només pel gust d'intercanviar informació, sinó amb l'objectiu de possibilitar la millora de les eines clau per a la recerca d'uns temes que algunes científiques $\mathrm{i}$ alguns científics socials creuen fonamentals a l'hora d'analitzar la realitat que ens envolta. 